\title{
Techno-Economic Evaluation of Optical Access and Metropolitan Area Networks: The Influence of the Status of Maturity of the Photonics Component Industry
}

\author{
Dimitris Varoutas, Thomas Kamalakis, Dimitris Katsianis, \\ Thomas Sphicopoulos ${ }^{1}$ and Thomas Monath ${ }^{2}$ \\ ${ }^{1}$ Department of Informatics and Telecommunications, University of Athens, Greece, GR-15784 \\ ${ }^{2}$ T-Systems Nova GmbH, Goslarer Ufer 35, D-10589 Berlin, Germany \\ arkas@di.uoa.gr
}

\begin{abstract}
A techno-economic evaluation of the business aspects of optical networks in the access/metro optical networks is given and its relation to the evolution of the photonic component industry is highlighted.

(C)2003 Optical Society of America

OCIS codes: 130.1750 Components; 130.0250 Optoelectronics
\end{abstract}

\section{Introduction}

The growing demand for new broadband services brings network operators towards the problem of increasing bandwidth requirements, especially in core and metropolitan area networks. In many cases new infrastructure and equipment is required for the provision of advanced services to end customers. In the early 90's many experts proposed an evolution towards Fiber-to-the-Home (FTTH). However economic and financial reality indicates that such solutions, if realized at a large scale, would result excessive investments and slow rate of return. On the other hand, depending on the specific conditions of each area, Fiber-to-the-Cabinet (FTTC) and Fiber-to-the-Office (FTTO) [1] seem to be better choices.

This paper presents an techno-economic analysis of metro/access optical technologies based on FFTH/O and FTTC based on either Ethernet point-to-point or ATM point-to-multipoint technology (Figure 1). The techno economic methodology and the associated tool has been developed within a series of EU funded projects which have studied various upgrade or deployment scenarios for telecommunication networks both optical and wireless [2],[3].

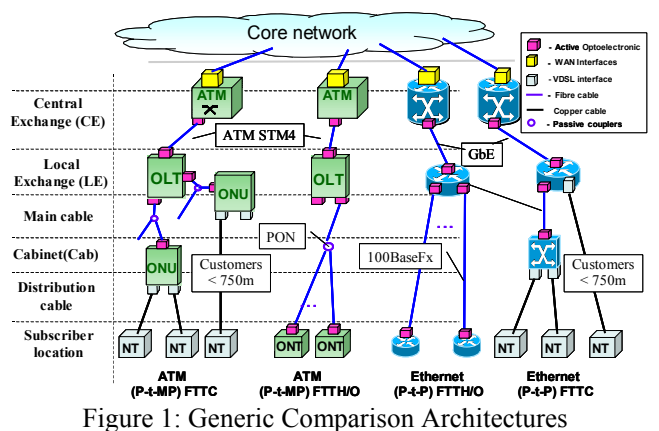

The model's operation is based on its database, where the cost figures of the various network components are kept and are constantly updated from data gathered from the biggest European telecommunication companies. A geometric area model is used to calculate the number of network elements as well as their cost, for a given set of services and network architectures. The geometric model is also used to estimate the cable infrastructure costs taking into account subscriber density, duct availability, and type of civil works. The future market penetration of these services and the tariffs associated with them, are calculated through market forecasts and benchmarking and are inserted into the tool. The TONIC tool then calculates revenues, investments, cash flows and other financial results for each year of the study period.

\section{Price Evolution Forecasting}

Price forecasting is an essential part of the techno economic methodology used in this study and is carried out by 


\section{JThA87.pdf}

the for the price evolution over time $P(t)$ using the extended learning curve [4]:

$$
P(t)=P(0)\left[n_{r}(0)^{-1}\left\{1+e^{\ln \left[n_{r}(0)^{-1}-1\right]-\frac{2 \ln 9}{\Delta T} t}\right\}^{-1}\right]^{\log _{2} K}
$$

In (1), $n_{r}(t)=n(t) / \max \{n(t)\}$ and $n(t)$ are the normalized and the actual accumulated production volume of the product at time $t$ respectively and $\Delta T$ is the growth period of the product defined as the time taken for the total production volume to reach from $10 \%$ to $90 \%$ of its maximum value. $K$ is the learning curve coefficient.

A generalization of the logistic model can be used for demand forecasts. The 4-parameter logistic model used for demand forecasts was introduced in [2] and is described by

$$
Y(t)=S\left(1+e^{a+b t}\right)^{-c}
$$

where $Y(t)$ represents the demand (penetration) of the service in a specific population, $S$ represents the saturation level of penetration and $a, b, c$, are parameters related to the characteristics of the curve. Such models are based on the diffusion theory, a methodological approach used for estimating the adoption of technological innovations or other products or services.

\section{Area Geometric Model}

The area is described in terms of subscriber density, loop lengths, geographical and market characteristics. The network model for the selected case study regarding urban areas is based on the Metropolitan Access Network (MAN), starting from the Central Exchange (CEx) and comprising the whole access network all the way to the customers. It is assumed that the Central Exchange (CEx) area encompasses and concentrates four Dense Urban, or four Urban, or eight Suburban Service Access Areas. Dense Urban and Urban Service Access Areas under study serves 16,384 and Suburban 8,192 customer units. For each Service Access Area all customers are connected to the same Local Exchange (LEx). The total number of customer units connected via POTS lines to one CEx thus amounts to 65,536 for all scenarios, which is the same derived by multiplying the number of buildings with the number of subscriber per building. The three different area structures are characterized in terms of the mean cable length connecting the subscribe to the LEx, the density of subscribers, the number of building, the number of subscribers per building, the duct availability between the LEx and the cabinets and the duct availability between the cabinets and the buildings. Figure 2 illustrates the access network distribution structure and the geometric model for the dense urban area. The model has been developed as a total of eight flexibility points (network levels) (FP) and seven link levels (LL). The cost of digging up trenches, installing ducts and cables, is crucial for the economics of any telecommunications network infrastructure and are calculated using this geometric model.

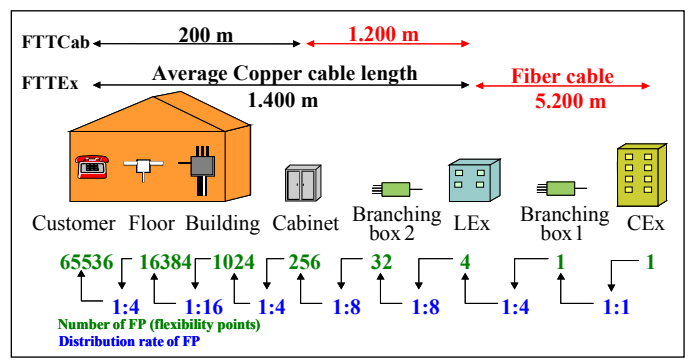

Figure 2: Distribution Structure and Geographic Model of the Dense Urban Area

\section{Results}

The Net Present Value (NPV) and the Payback period have been used for the sensitivity analysis as financial criteria. The discount ratio (reflecting the cost of capital and the associated risk) is taken 10\%. Figure 3 shows the NPV for both the FTTC (figure 3(a)) and the FTTH/O (figure 3(b)) Ethernet deployment scenarios in dense urban areas. As shown in figure 2 the NPV for the FTTC scenario is $€ 30 \mathrm{M}$ mill and much higher than that of FTTH/O $(€ 8 \mathrm{M})$ which is to be expected mainly because of the increased cable installation cost in the latter scenario. Both 


\section{JThA87.pdf}

business cases however have a positive NPV. In order to estimate the impact of the various factors determining the NPV for each network scenario, sensitivity analysis is used. Sensitivity analysis is based on studying the impact of a single market parameter without any changing any other parameter. The sensitivity results are presented after the identification and ranking of the most critical parameters with the greatest impact. In figure 2(a) the NPV sensitivity analysis results are presented for the FTTC architecture. We observe that for a $20 \%$ increase in the total penetration the NPV rises as high as $37 \mathrm{M} €$, implying an increase of $23 \%$ in the total investment value.

Figure 12 also shows that in both FTTC and FTTH/O architectures the price evolution for the components is of importance. Unfortunately however, even in the case that the prices within a ten years period fall down to the $33 \%$ of the 2003's level, the deployment is mandated mainly from economical and not from technological factors. This is due to the fact that technology (especially optoelectronics) contributes less to the overall investment cost even in the FTTC scenario. As the labour/installation costs contribute as much as $62 \%$ to the overall and hence expenditures are mainly dominated by this factor. In suburban areas, this cost contribution will be even higher and hence even more unfavorable figures are to be expected in this case.

(a)

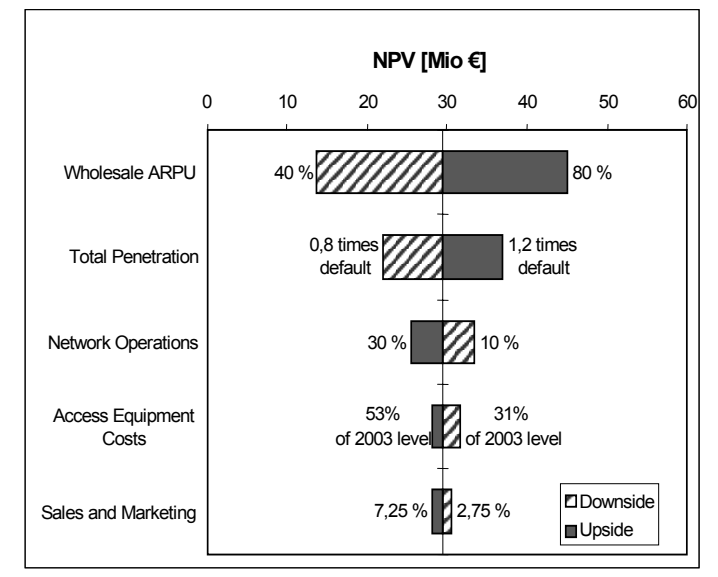

Figure 3: Access equipment cost evolution is more highly critical for FTTO/H deployment (b) than for FTTC

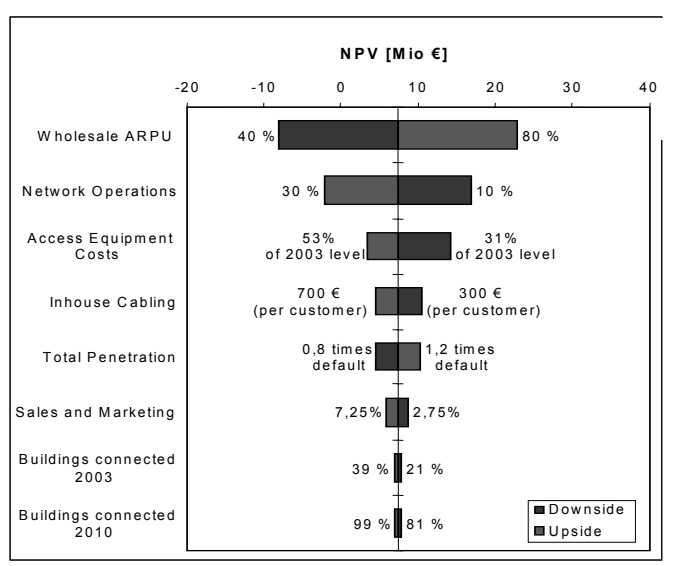
architectures (a). ARPU=Average Revenue Per User.

\section{Conclusions}

IA methodology for determining the impact of various key factors influencing the economic viability of metro/access optical network upgrades was presented. The prospects of both FTTC and FTTH/O deployments based on Ethernet technology from the viewpoint of an incumbent network operator were considered. The business cases studies show that the success of the FTTC and FTTH/O deployments are determined mainly from economic and market issues (tariffs, demand) rather than technological ones. Existing technology was shown favor investments in dense urban areas and particularly FTTC. FTTH/O results in longer pay-back periods and should therefore wait for a either more mature market or technological improvements, or otherwise operators must accept longer Pay Back Periods. Investments in photonic component technology can lead to shorter payback periods and consequently, additional cash flows. These cash flows could be used for further investments in order to provide advanced broadband services to end users especially in urban and suburban areas as well as to other non-completive areas in general. Since price evolution of components is not linear and rather logarithmic with respect to production volumes, mass production of optoelectronics can turn unfavorable cases to successful ones. In conclusion, investments in technology can develop new values besides the traditional ones adopted by the operators, which are based mainly on new service development and operational cost savings.

\section{References}

[1] R. Ramaswami et al Optical networks: a practical perspective, Morgan Kaufmann Publishers, 2002.

[2] EU TONIC, IST-2000-25172. Available at http://www-nrc.nokia.com/tonic/

[3] ECOSYS, Available at http://www.celtic-ecosys.org/

[4] B. Olsen et al, Telektronikk, 100 (4), 138-148, 2004 